\title{
Editorial
}

\section{To Humankind}

\author{
Houssam KHELALFA (Editor in Chief \& Founder) ${ }^{1,2,}$
}

\author{
${ }^{1}$ LGCE, University of Jijel , Jijel, Algeria \\ 2 School of Social Mathematical \& Human Engineering Sciences, Selinus university of science and literature \\ (SUSL), Bologna, Italy \\ *Correspondence: khelalfahoussam@gmail.com; Tel.: (+213 697601 497)
}

How to cite this paper: Khelalfa, $\mathrm{H}$ (2021). To Humankind. Journal of Social Mathematical \& Human Engineering Sciences, 1(1), 1-2. https://doi.org/10.31586/jsmhes.2021.124

Published: September 07, 2021

Copyright:@ 2021by the authors. Submitted for possible open access publication under the terms and conditions of the Creative Commons Attribution (CC BY) license (http://creativecommons.org/licenses /by/4.0/).
As a scientific researcher, I have always wondered, how, despite all these precise sciences and the broad disciplines that man has discovered and developed throughout history, we still suffer from wars and the lack of world peace?, How can all these sciences not produce world peace ?. But by my belief in humanity's passion and desire for peace, despite the various reasons that undermine it; which I consider to be based on the failure to see the complete picture of the world, ignorance of its nature and its essence, and not realizing all the actual dimensions that exist in the life, Also, believing in the capacity of science to embody this peace and to elevate humanity towards transcendence and harmony, so; I have always thought that there is an incomplete science that we have not yet perceived, whose role is to activate the international community and achieve international balance and peace through an international equation that can be called "Global Peace Equation".

The opening of this journal is the first practical step in the history of science in order to embody the theory of combining the social sciences and humanities with mathematics and engineering sciences as a new unified science, in order to search for world peace through science by finding the global peace equation, which I consider it the ultimate goal desired to be reached through this new science. This journal is considered a fundamental pillar for building the scientific material for this new science by applying all the scientific theories in the humanities and social sciences mathematically and engineeringly and vice versa, also, creating and applying new theories and models. Since in my theory I have established the mathematical coordinate system as a principle for social mathematical and human engineering sciences on which all calculations and applications will be done, and I have established basic concepts and principles in psychological engineering, social engineering, economic engineering and political engineering ...etc. But I would also like to note that this journal is not necessarily limited to the exclusive development of the above theory, as it welcomes all papers that integrate mathematics, engineering and applied sciences with the social sciences and humanities and vice versa, therefore, we will leave the field open to everything that can lead us to achieve our long-term goal, and for all relevant research, because building a new science requires ideas that may be very primitive, but their future results are important.

As the founder and editor in chief of the journal, I will spare no effort in building this science step by step and working on the roadmap that has been set by observing ideas, theories and suggestions and directing research and publications towards achieving the desired vision. I will also work on a unique and rigorous peer review mechanism; given that any article is a multidisciplinary research and therefore it is necessary to call up experienced reviewers for each integrated thematic, where the focus of each of them will be in his discipline, and in the end, the final result will be appropriate on the basis of the journal's goal by the editorial board. I would also like to thank very deeply and with great 
gratitude the Science Publications(SCIPUB) for accepting the project of establishing this journal (JSMHES), for their belief in the idea and for giving me this great opportunity to embody my theory, which for me is a great common humanitarian goal that is now beginning to achieve.

The opening of this journal as a first step is the most important, Which will be followed in parallel by the opening of a school of Social Mathematical \& Human Engineering Sciences at the Selinus University of science and literature (SUSL) to launch research projects and start building a model for teaching social mathematics and human engineering as a new academic field and for coordination between the various actors in the world as a second and complementary step in the path of this ambitious human project, Hoping from this science to provide humanity with the desired harmony by proving to them scientifically and practically that everything was created by measure and that everything is in a balance, and believing that human solidarity is stronger than dispersal and that human wisdom is stronger than vanity and recklessness; wherefore, I recommend that this be an international project in which all people, countries and organizations all over the world contribute in, as I am sure that future generations will achieve the great equation. 